\title{
AS BODAS SINTOMÁTICAS DO OBSESSIVO COM A HISTÉRICA
}

Antônio M. R. Teixeira

Médico psiquiatra; professor adjunto da Faculdade de Filosofia e Ciências Humanas da UFMG; doutor em Psicanálise (Champ Freudien - Paris VIII).
RESUMO: Ao considerar o sofrimento gerado pelas relações amorosas como causa de demanda terapêutica, na clínica psicanalítica, procurou-se interrogar aqui em que sentido o parceiro sexual pode vir a constituir um sintoma para o sujeito. No encaminhamento dessa questão, examinou-se, mais especificamente, o modo de parceria sintomática entre sujeitos obsessivos e histéricos, apoiando-se na teoria psicanalítica do parceiro sintoma. Procura-se demonstrar de que maneira os sujeitos histéricos e obsessivos respondem, no nível dessa parceria, aos impasses engendrados pela ausência de inscrição simbólica da relação sexual.

Palavras-chave: Psicanálise lacaniana, histeria, neurose obsessiva, parceiro sintoma.

ABSTRACT: The symptomatic wedding of the obsessive with the hysterical. When considering the suffering produced by loving relationships as the cause of therapeutic demand in the psychoanalytic clinic, we try to discuss the way in which a sexual partner can become a symptom to the subject. In the treatment of this issue, the author has examined, more specifically, the mode of symptomatic partnership between obsessive and hysterical subjects, relying on the psychoanalytic theory of the symptom partner. In this way, the article shows how obsessive and hysterical subjects respond, at the level of this partnership, to the impasses related by the absence of the symbolic inscription of the sexual report.

Keywords: Lacanian Psychoanalysis, hysteria, obsessive neurosis, symptom partner. 
A questão era saber qual é essa impulsão secreta qui nos conduz mais a uma pessoa do que a outra, antes mesmo de conhecer seu mérito...

(Pergunta da Rainha Cristina da Suécia, em carta endereçada por Chanut a Descartes, no dia 11 de maio de 1647)

$\Lambda$ quem leu o caso clínico, descrito por Freud, do Homem dos Ratos, não passou certamente despercebido o dilema vivido por Ernst Lanzer, diante da dificuldade em escolher sua parceira: sua indecisão quanto a desposar a mulher rica ou desejar a mulher pobre revela algo de paradigmático na própria estrutura da neurose, para além dos diversos estados de hesitação patológica que lhe acometiam (FREUD, 1906/1999, p.420). Interessa-me salientar aqui que se a mulher, cuja escolha o obsessivo protela, apresenta-se ora investida de um excesso, na forma da mulher rica, ora marcada pela carência, na apresentação da mulher pobre, o que se encontra subjacente a seu dilema diz respeito à ausência de uma justa medida do valor que se pode a ela atribuir. ${ }^{1}$

Se me proponho então a dissertar sobre o par formado pelo casamento do obsessivo com a histérica, é porque me parece importante discutir o modo como tal parceria vem constituir uma solução sintomática para o problema dessa ausência de medida na relação entre os sexos. Não se trata, bem entendido, de identificar simplesmente o obsessivo com o homem e a histérica com a mulher; nada efetivamente impede de localizar, do ponto de vista de uma observação empírica, mulheres obsessivas e homens histéricos. O que está em questão é, antes, saber como essa parceria funciona enquanto resposta do ser falante à ausência de medida entre os sexos, ausência esta que, em Lacan, se formula como a não-existência do rapport sexual.

Não é, decerto, por pedantismo que o termo rapport aqui se encontra mantido em francês, sem tradução. Se ele ali permanece é porque não me parece exato afirmar que, para Lacan, a relação sexual não existe. O que não existe é o rapport sexual, cabendo lembrar que o termo rapport não equivale ao que em nossa língua entendemos por 'relação'. Ele significa, mais especificamente, 'relação de medida' ou de 'proporção'. A relação sexual inegavelmente existe, conforme se atesta nos pares sintomáticos modernos, em seus infindáveis esforços para discuti-la. O que não existe é a proporção, a inscrição simbólica da medida do par sexual.

Pode-se, aliás, verificar que a falta de uma medida de proporção simbólica, relativa à escolha do parceiro amoroso, já havia sido tratada por Lacan bem antes de estabelecer a fórmula relativa à ausência do rapport sexual. A maior parte do comentário por ele dedicado, ainda em 1960, ao personagem Pau-

\footnotetext{
${ }^{1}$ A esse propósito, leia-se, de Jacques-Alain Miller, “Un répartitoire sexuel”, in La Cause Freudienne n. 52, Paris, ECF, abril, 2002.
} 
sânias, do Banquete de Platão, no capítulo intitulado "A psicologia do rico", do Seminário VIII, já se organizava em torno da impossibilidade de se estabelecer um padrão de valor na parceria amorosa. Todo o esforço de Pausânias converge para uma tentativa de definir essa escala de valor conforme a distinção, por ele desenvolvida, entre o amor representado pela Afrodite uraniana, nascida da chuva engendrada pela castração de Urano por Zeus - sem relação, portanto, com a diferença dos sexos — e pela Afrodite Pandêmia, oriunda da união sexual de Zeus com Dione. A primeira Afrodite, a uraniana, corresponderia ao amor próprio aos filósofos, representado pela conjunção homossexual da qual se compõe a relação do mestre com seu jovem discípulo, amor ao qual se impõem regras que justifiquem o investimento amoroso do amante (érastes) sobre o seu objeto (éromenos). Já a segunda Afrodite, a Pandêmia, é a Vênus popular em cuja representação se misturam todos os amores, indiferente às escalas de valor. Ela seria a deusa do amor suscitado pela contingência do encontro sexual, alheio, portanto, às considerações sobre o mérito do objeto amado.

Se a chave dessa passagem do Banquete se encontra, conforme lhe sugeriu A. Koyré, na crise de soluços de Aristófanes, após o discurso de Pausânias, é porque Aristófanes na verdade teve uma crise de riso ao ouvir seu antecessor. O risível aqui diz justamente respeito ao esforço, empreendido por Pausânias, de estabelecer essa escala de valor do objeto amoroso. Sua concepção resulta, observa Lacan, de um discurso elaborado em função de uma cotação de valores: trata-se de saber como aplicar seus fundos de investimento libidinal, de assegurar-se que eles não serão desperdiçados com rapazolas que não valem a pena. Seu ideal é a "capitalização protegida, o depósito em cofre do amor que lhe pertence por direito”. No impasse dessa avaliação do amor, comicamente celebrado pelo riso de Aristófanes, Lacan situa a miragem de toda medida relativa ao encontro sexual, na psicologia do rico. Ela é o que leva Pausânias a dizer que aqueles que não são dignos do amor uraniano, ou seja, que não dão garantias de retorno ao investimento libidinal do érastes, que recorram à Vênus Pandêmia, a grande libertina. Ou seja (a expressão é de Lacan): “que vão se foder, se é isso que querem" (LACAN, 1960-1961/1992, p.66).

No intuito, portanto, de abordar a relação sexual que existe, e que se configura em resposta à não-existência dessa medida de valor que em Lacan mais tarde se formula como ausência do rapport sexual, seria preciso retomar o problema na perspectiva do parceiro sintoma, do momento em que a relação sexual, como se verá, somente existe sintomaticamente. Conforme iremos esclarecer, o sintoma é a própria resposta que o sujeito constrói para se haver com a ausência do rapport sexual. Para nos valermos então de um polo de orientação para nosso argumento, partamos do fato explicitado por Jacques-Alain Miller, em sua Teoria do Parceiro, de 1996, de que quando Lacan formula que o rapport sexual não existe, ele o faz 
diante da constatação da ausência de qualquer saber que diga respeito ao que nos conduz ao parceiro sexual. Isso quer dizer, simplesmente, que o parceiro sexual não tem, para o ser falante, nenhum endereçamento programado. O impossível do rapport sexual diz respeito "a um real que a experiência psicanalítica testemunha, sem contudo poder demonstrá-lo”, a partir da contingência invariavelmente presente no encontro com o outro sexo (MILLER, 2000, p.154-155).

O contingente prova assim o impossível: se não encontramos, nem mesmo em René Descartes, um conjunto de “Regras para a direção da libido”, é porque não há meios de se programar, por uma cadeia de razões, o vetor que oriente o ser falante a uma escolha de objeto determinada, do momento em que não há rapport sexual, em que não há inscrição simbólica no que diz respeito à relação ao sexo. Distintamente da admiração que visa o Ideal e pode, dessa forma, servir de orientação para o ser falante, o amor não visa ao ideal no parceiro. O amor antes supõe, prossegue Jacques-Alain Miller, que o sujeito perceba no parceiro não o ideal, mas o sintoma que ele elaborou para dar conta da ausência de rapport sexual. E uma vez que não existe solução simbólica da relação do sujeito com o gozo sexual, o que se busca no parceiro sintoma, vem a ser justamente o objeto que se subtrai à ordem significante, designado por Lacan pelo o nome de objeto a.

Ao se tomar por referência então o rapport sexual, cuja impossibilidade se atesta pela invariável contingência que preside a todo encontro amoroso, chega-se ao necessário da relação sexual sintomática como aquilo que não cessa de se escrever para o ser falante. Conforme se pode ler na lição XI do Seminário Mais ainda, é somente no nível desarmônico do sintoma, em que se marca, para cada um, o rastro de seu exílio do rapport sexual, que algo se pode se inscrever como relação necessária. Nessa perspectiva, a psicanálise faria bem de lembrar aos terapeutas de casal que quando o sujeito se queixa de tal parceiro, isso não significa que esse parceiro seja inadequado. Ele talvez seja antes, enquanto parceiro sintoma, aquele que melhor se presta à manutenção do par conjugal.

Voltemos agora, munidos desses esclarecimentos, ao par sintomático que dá título ao nosso tema: o casamento da histérica com o obsessivo. Pois muito embora a percepção desse par, com todos os dramas banais que ele comporta, preste-se no mais das vezes a comentários maliciosos ou a versões anedóticas do casal tipo - impossível não evocar aqui os tão proverbiais casamentos da psicóloga com o engenheiro, ou da artista plástica com o empresário —-, nem por isso devemos nos furtar a examinar ali determinados aspectos estruturais da relação do sujeito para com o desejo. O que então dizer do par sintomático composto pela histérica e pelo obsessivo? Quais aspectos essa parceria nos revela acerca da estrutura da relação do sujeito para com o desejo? 
Antes de encaminhar tais perguntas, eu faço apelo a uma certa benevolência do leitor, colocando-lhe a par das dificuldades que se apresentam no tratamento do tema. A bem dizer, eu somente encontrei, ao termo de uma vasta pesquisa da obra de Lacan, apenas uma indicação desse par sintomático. Ela se encontra formulada uma única vez, no último parágrafo da p.415 da versão brasileira do Seminário $V$, num momento em que Lacan faz referência ao fenômeno da anulação do grande Outro, na constituição do desejo obsessivo. Segundo Lacan, diante do fato dessa anulação do Outro, é somente mediante à redução do parceiro à condição de objeto, ou seja, mediante a destituição do que determina o parceiro como sujeito no campo do Outro, que o sujeito obsessivo encontra um apoio para o seu desejo. Se todo o problema do obsessivo, prossegue Lacan, está em encontrar para seu desejo um parceiro situado na condição de objeto, essa condição corresponde ao ponto que a histérica, por força de suas identificações, ocupa com tanta facilidade, ou seja, de estar em frente ao sujeito como objeto pequeno a. ${ }^{2}$ Mas o que vem a ser então, se quisermos prosseguir nessa via, esse fenômeno de anulação do Outro que se manifesta na constituição do desejo obsessivo? E em que sentido a histérica a ele responde na posição em que ela mesma perde sua cidadania de sujeito no campo do Outro, ou seja, na condição de objeto a?

Pois bem. Conforme dizíamos mais acima, se o par amoroso se constitui como sintoma enquanto solução subjetiva ao exílio do rapport sexual, esse exílio de que fala Lacan diz respeito justamente à ausência, no campo do Outro, de uma solução significante integral para essa relação. Concluímos portanto que há um resíduo que escapa à ação do simbólico, resíduo cujo signo, afirma Lacan, determina a marca a que o sujeito se dirige para se haver com o que, para além da cadeia significante, diz respeito a seu desejo. É importante enfatizar que Lacan faz apelo à noção de signo, em tal momento, para indicar o resíduo dessa relação subjetiva ao desejo que escapa à ação do significante, sobretudo se considerarmos a retomada crucial dessa mesma indicação no Seminário Encore: o mesmo Lacan que, em 1958, permitia-se fazer referência ao signo para tratar dessa dimensão do desejo que escapa às leis do significante - como se pode verificar em seu comentário sobre o sonho da bela açougueira (LACAN, 1957-1958/1998, p.379), irá propor definir a demanda de amor 14 anos mais tarde, no Seminário XX, como uma demanda de signos, por considerar justamente a ausência de uma solução significante plena para o rapport sexual (LACAN, 1972-1973/1975, p.40). É porque o signo não é o significante que Lacan a ele recorre para pensar esse resíduo. Mas vejamos em que sentido.

\footnotetext{
${ }^{2}$ Há aqui, como se percebe, uma formulação que converge para aquilo que Freud descrevera, em sua Psicologia da vida amorosa, a propósito de uma tendência universal à depreciação na esfera do amor.
} 
Ao se considerar como um signo diferencia-se de uma declaração significante, um aspecto que se destaca, dessa diferença, diz respeito ao fato de que o significante depende da cadeia na qual ele encontra inserido, ao passo que o signo se estabelece como tal justamente a partir da ausência dessa articulação prévia. Falamos, pois, de uma conversão do significante em signo quando ele se desarticula da cadeia, assim como pensamos numa conversão do signo em significante quando ele vem a ser interpretado, o que no caso quer dizer reencadeado, re-inserido numa cadeia significante. É o que nos deixa entender Lacan em seu Seminário VIII, na seção intitulada “o não de Sygne”, ao comentar a primeira peça da trilogia de Paul Claudel. A saber, que diante da impossibilidade em que se encontrava Sygne de articular um não como recusa à proposta obscena que ela deveria obrigatoriamente aceitar — qual seja: esposar aquele que executou seus pais e lhe ceder o nome e as posses de sua família —, só lhe resta, ao final da peça, acenar um signo de não com um gesto de cabeça que ela repete, incessantemente, como um sintoma psicossomático, até o momento de se dar a morte.

O signo não é, portanto, o significante, cujo funcionamento depende da cadeia em que se encontra articulado. Diversamente do significante, o signo seria, por assim dizer, um significante desencadeado, um elo desligado da cadeia significante. Ele não funciona como o significante, que se explicita em seu próprio uso, ao representar o sujeito para os demais significantes. Nesse sentido, enquanto elo separado da cadeia, o signo suscita, em quem o vê, uma interpretação para produzir um significado. Ao representar algo para alguém, o signo engaja esse alguém ali suposto, como sujeito, na composição, a seu redor, de um encadeamento simbólico que lhe dê sentido. Quando afirmamos, por exemplo, que o sujeito ciumento é ávido por signos, é na medida em que, para ele, os signos correspondem à evidência de uma verdade não declarada. Sempre que se suspeita de uma significação não articulada na cadeia significante, fica-se à espreita de signos sobre os quais se possa tecer algum tipo de interpretação.

O signo só significa, portanto, se vinculado a um contexto que dele faz um enunciado legível. Seu valor não é unívoco: a fumaça, ironiza Lacan, não é necessariamente signo do fogo; ela pode muito bem não mais ser do que signo do fumante. O mesmo se nota, por exemplo, no signo do silêncio que por vezes angustia o conferencista, quando ninguém na plateia se manifesta ao término de sua fala. Pois é fato que, contrariamente ao que enuncia o provérbio, quem cala nem sempre consente, calar é muitas vezes uma forma de se dizer não. Somente a expectativa de uma resposta torna, por assim dizer, o silêncio gritante, na medida em que a resposta ansiosamente aguardada decide pelo valor a ser dado a uma demanda premente. E esse silêncio, como dizem os apaixonados, torna-se ainda mais gritante quando a demanda da qual se trata vem a ser uma 
demanda de amor. Cabe elucidar então em que sentido a demanda de amor pode ser concebida como uma demanda de signo, para entender enfim como o obsessivo e a histérica sintomaticamente se comunicam nessa relação.

Não foi preciso esperar a psicanálise, evidentemente, para descobrir que o amor se faz entender mediante signos. Trata-se de uma constatação antiga, familiar aos autores românticos, que Freud, aliás, menciona em sua conferência introdutória sobre os atos falhos. Se devemos captar, na sutileza de uma palavra que interrompe o curso da cadeia falada, em um gesto que se desvia da intenção do agir, o signo de uma formação do inconsciente, a aparência insignificante desses fenômenos, adverte Freud, não deve levar o observador a subestimar sua importância e a deixar de examiná-los. Tal é igualmente o caso, diz ele, da paixão amorosa, que quase nunca se revela ao amante por uma declaração frontal. Ela antes se faz notar mediante signos sutis, como um desvio do olhar, um sinal que, por exemplo, pode não mais ser do que o prolongamento, por um segundo, de um simples aperto de mão. Seria, contudo, um engano afirmar que os signos do amor são perceptíveis somente a quem ama. Aliás, tamanha é, por vezes, a profusão erótica de signos, que existe mesmo uma semiótica, que remonta à Renascença, concebida para descrever os sinais do desvario amoroso na tipologia de uma patologia da alma. Pode-se, facilmente, encontrar, em Panofsky, a descrição da sintomatologia amorosa em seus efeitos de entorpecimento e cegueira, a partir de seu comentário sobre o termo cupiditas (PANOFSKY, 1967, p.160-166). O amor se vê ali figurado como uma doença que infantiliza suas vítimas, ao privá-las da capacidade de julgamento, conforme evoca a imagem travessa de Cupido com os olhos vendados, cujas asas indicariam, de acréscimo, a volatilidade das emoções amorosas.

Lacan também não contesta, como bem sabemos, que o amor faça signo, nem tampouco se dispensa de considerar sua semiologia. Mas não sem acrescentar que o signo do amor diverge-se dos demais signos, no sentido em que ele demanda algo mais do que uma simples interpretação. Longe de se resolver em uma composição significante determinada, o amor, por ser pedido de amor (assim como o desejo é desejo de desejo), é signo que acena para outro signo, instaurando, desse modo, sua demanda sob a égide da insatisfação. Se do amor procede a contínua demanda por “mais, ainda”, que dá título ao Seminário XX, é porque o signo ao qual ele visa jamais encontra uma solução significante satisfatória no campo do Outro. Tal signo ininterpretável corresponde, na realidade, à tentativa, que o amor sinaliza, de ignorar a separação dos sexos, ao buscar estabelecer a medida impossível do rapport sexual. Impossível, como já o dissemos, na medida em que o sexo inscreve, no ser falante, a diferença que funda a articulação de toda cadeia significante, sem que haja, no registro significante, nenhuma fórmula que possa redimir essa diferença na unidade programada de uma relação. E uma vez que a 
identidade do ser, à qual visa o amor, encontra-se fora do registro da linguagem que só habilita as distinções, é preciso, para provocá-lo, interpor o signo como elemento suplementar de enigma, desarticulado da cadeia significante (LACAN, 1972-1973/1975, p.40). Esse signo é o que sustenta, como se pode suspeitar, a dimensão imaginária do falo da qual o sujeito se vê privado, sinalizando o objeto causa de desejo que nenhuma composição significante preenche, mas que permanece, enquanto promessa, no horizonte de sua impossível satisfação.

Por carecer, assim, de uma solução significante plena, o amor quase sempre toma, para o sujeito apaixonado, as feições inquietantes de uma eleição caprichosa. "Amo você apesar de você", lamenta-se o sujeito amoroso, quando já não mais entende o que o faz persistir numa infeliz escolha. "Não consigo entender o que você vê nele”, exclama exasperado o amante não correspondido, tentando em vão decifrar, mediante comparações imaginárias com seu rival, o signo que ele não mais exibe para sua amada. Podemos então dizer que a resposta do sujeito neurótico consiste, conforme a experiência clínica instrui, em negar essa virtualidade enigmática da escolha amorosa, sobretudo na neurose em sua versão obsessiva. O sujeito obsessivo se concentra, por assim dizer, na tentativa de apagar a contingência dessa escolha, acreditando poder inscrevê-la na ordem de uma necessidade dedutível. Por isso, ele não mede esforços para tecer, diante dos frequentes desencontros que a experiência do amor produz, sobretudo em sua parceria sintomática com a histérica, seu por vezes comicamente sofisticado sistema de explicação: "Foi algo que fiz? Que deixei de fazer? Que deixei de dizer com relação ao que fiz?” etc.

Ocorre perceptivelmente, nessa parceira sintomática, um processo em que a histérica coloca o obsessivo numa condição de trabalho constante, ofertando-lhe signos que ele se exaure a decifrar, sem jamais produzir uma solução definitiva. O obsessivo se extenua, por assim dizer, a encadear o signo suplementar do amor no discurso pela via do significante fálico. Vale lembrar aqui o quanto o neurótico diverge, com relação a esse ponto, da atitude do sujeito psicótico. O psicótico não perde seu tempo tentando em vão deduzir a natureza da composição fálica que o torne desejável, como faz o neurótico. Ele não ignora o aspecto arbitrário inerente a toda escolha amorosa. Ao se ver confrontado com a dimensão do amor, o psicótico não busca construir um sistema explicativo que dissolva sua contingência. Ele, antes, dá a esse capricho o destino que, a rigor, ao capricho pertence, no interior de um sistema lógico: o de ser um axioma, um postulado não dedutível do qual o delírio seria a derivação formal. É nesse sentido que se pode pensar o postulado erotomaníaco descrito por Clérambault, assim como a dimensão da certeza enigmática em torno da qual se organiza o delírio, na psicose. 
Como se explica então, para voltarmos ao nosso tema, que o sujeito obsessivo passe seu tempo tentando deduzir essa dimensão do amor que escapa às leis do significante? Qual fator determina essa condição que o condena à tarefa constante de reduzir o desejo à necessidade?

Ora, tudo gira em torno, como se pode perceber, da dimensão do desejo que se coloca como um para além da demanda, um para além do que se pode articular no nível do significante. No caso da histeria, a solução consiste em fazer valer esse para além na forma do desejo recusado, daquilo que se oferece sem deixar alcançar. A provocação histérica, explicita Lacan, tende a constituir o desejo como algo apresentado por detrás de um véu, sem que esse algo possa ali ser encontrado. Não vale abrir meu corpete, provoca a histérica, porque você ali não encontrará o conteúdo fálico, mas se insinuo que olhe o meu corpete, é para que você aponte, por detrás do corpete, o falo não enquanto conteúdo, mas enquanto significante do desejo recusado (LACAN, 1957-1958/1998, p.393).

Porém, o ponto fundamental é que nesse para além encontra-se algo diante do qual o Outro perde sua prevalência. O que se encontra nesse para além, prossegue Lacan, é precisamente o caráter em que se apresenta o desejo como tal: ao se afirmar como condição absoluta, o desejo coloca fundamentalmente em causa a consistência do Outro, já que, no campo do significante em que o Outro consiste, nada existe como absoluto, tudo se coloca perpetuamente em relação, significante a significante. Há, portanto, no desejo como condição absoluta, uma exigência que prescinde do Outro, na qual o Outro não tem que responder sim ou não.

No que diz respeito à solução histérica, esse além da demanda se situa sob a forma de um desejo referido desejo do Outro. Isso não quer em absoluto dizer que a histérica visa a se alienar no campo do Outro, no sentido de respeitar suas regras, pois assim não haveria um para além. Sua solução consiste antes em suscitar esse para além ao fazer desejar o Outro. Ela provoca o desejo do Outro mediante um enigma acerca do seu próprio desejo, que pode bem ser, como no caso de Madame Bovary, um estado de perpétua insatisfação. Ela lhe oferta esse enigma como um sintoma a ser decifrado, ou seja, como um $x$ para o qual não existe solução preparada no nível da articulação significante.

Quanto ao obsessivo, ele também visa, tal como a histérica, o desejo para além da demanda, mas com uma significativa diferença. Diversamente da histérica, cujo desejo visa o desejo do Outro, o sujeito obsessivo, para atingir o além da demanda, antes nega o elemento de alteridade incluído na demanda de amor. Para conservar o incondicional da demanda, transformando-o em condição absoluta do desejo, o Outro é negado, fazendo com que esse caráter incondicional seja transferido para o plano da necessidade. Daí se explica, segundo Lacan, nas assim chamadas ideias fixas da criança obsessiva, essa exigência desmedida e intolerável 
por algo sem importância, como ocorre quando se diz que ela cisma com alguma coisa. Não se tem mais uma demanda como as outras, mas uma demanda com esse caráter de condição absoluta próprio ao desejo. O desejo é aqui a necessidade não dialetizável, que recusa a mediação do Outro para se deixar relativizar no nível da articulação significante (LACAN, 1957-1958/1998, p.414).

Mas há, como se pode ver, uma contradição interna na estratégia obsessiva. Pois, se por um lado, seu desejo depende do Outro em que se articula a demanda significante, a partir do qual se constitui o para além dessa demanda, por outro lado, ele é levado, em sua estratégia, a almejar a anulação do Outro como o que faz obstáculo ao desejo enquanto condição absoluta. Ele se vê, por conseguinte, conduzido a anular o Outro sobre o qual se apoia o seu desejo. Ora, uma vez que, nessa contradição, o sujeito depende do Outro como suporte, ao mesmo tempo que, em sua estratégia, visa a anulá-lo, o obsessivo se encontra perpetuamente condenado a restaurar a dimensão do Outro, da qual ele constantemente deseja o desaparecimento. Por esse motivo, observa Lacan, o obsessivo é um cerimonioso; ele está sempre pedindo permissão na exata medida em que a dialética com o Outro é por ele posta em causa. O obsessivo se empenha constantemente na sua restauração, de tal maneira que sua fantasia de oblatividade se interpreta como o apelo para que o Outro finalmente consinta com seu desejo.

Por isso ele faz de seu desejo um desejo imaginariamente sustentado pela proibição do Outro, para ter a quem pedir licença. Disso se explica, entre outras coisas, o suplício de Tântalo do sujeito obsessivo, cujo desejo desaparece quando o objeto a ele se entrega. Daí igualmente se explica porque a histérica, ao se fazer de objeto para o obsessivo, ela o faz na forma do objeto que se furta, que ele não pode deter. A provocação histérica visa, na realidade, tantalizar o sujeito obsessivo, na forma prosaica que boa parte dos homens conhecem: "mas não era nada disso que você estava pensando”. E isso finalmente explica, para concluirmos com Lacan, as proezas do obsessivo. Se o obsessivo se mostra tão adepto à ordem verbal, tão apto a se alienar nas regras, é porque precisa da testemunha invisível do Outro que ali está de espectador. Ele precisa sustentar o Outro como lugar onde se registra a façanha. Mas o que ele busca, em suas façanhas, é a permissão do Outro para gozar, gozar de algo que ele de fato mereceu, mas cuja satisfação não se classifica no campo em que ele acredita merecê-la. Ele se impõe as mais árduas tarefas, nas quais, aliás frequentemente obtêm sucesso, mas não goza das férias merecidas. Ele busca a permissão do Outro, mas o outro com quem ele tem que se haver, em sua parceria, não tem nada a ver com essa história. E no mais a histérica, a qual ele porventura se dirige, não tem nenhum motivo para coroar de êxito a proeza do obsessivo, já que ela, mais do que ninguém, sabe que o desejo do obsessivo não tem nada a ver com o campo em que o sujeito mostrou suas aptidões. 
Pelo contrário, nada melhor, para uma histérica, cujo desejo se sustenta no ato mesmo de suscitar o desejo do Outro, do que poder exibir, ao sujeito obsessivo, a veleidade de suas proezas. Pois se a histérica visa a um mestre, como representante do Outro no discurso, para revelar a sua castração, é justamente na medida em que a ela interessa a falta do Outro, ou seja, aquilo que dele faz um Outro desejante. Nesse sentido, a histérica revela, em seu casamento com o obsessivo, o quão vã é a sua alienação ao Outro do qual ele pensa poder obter a permissão. E na medida em que a histérica revoga do obsessivo o título de mestre a que ele acreditava ter direito por suas façanhas, que ela pode reconstituir-lhe, ainda que ao custo de sua angústia, a posição de sujeito desejante. E é talvez por isso que os analistas devamos, a essa parceira histérica, a chegada do obsessivo aos nossos divãs.

Recebido em 25/6/2008. Aprovado em 4/8/2008.

\section{REFERÊNCIAS}

FREUD, S. (1906/1999) “Bemerkungen über einen Fall von Zwangsneurose”, in Gesammelte Werke. Frankfurt: Fischer Verlag.

MILLER, J.-A. (2000) “Teoria do parceiro”, in Os circuitos do desejo na vida e na psicanálise. Rio de Janeiro: Kalimeros.

(2002) “Un répartitoire sexuel”, in La Cause Freudienne n. 52, Paris: ECF, abril, p.7-27.

LACAN, J. (1960-1961/1992) O Seminário Livro VIII: a transferência. Rio de Janeiro: Jorge Zahar.

(1957-1958/1998) O Seminário Livro V: as formações do inconsciente.

Rio de Janeiro: Jorge Zahar.

(1972-1973/1975) Le séminaire livre XX: Encore. Paris: Seuil.

PANOFSKY, E. (1967) Essais d'Iconologie. Paris: Gallimard.

Antônio M. R. Teixeira

amrteixeira@uol.com.br 